\title{
BMJ Open Trends in burden of work-related upper limb amputation in South Korea, 2004- 2013: a nationwide retrospective cohort study
}

\author{
Jun-soo Ro, ${ }^{1}$ Ja-Ho Leigh (D),${ }^{1,2,3}$ Inpyo Jeon, ${ }^{4}$ Moon Suk Bang ${ }^{1}$
}

To cite: Ro J, Leigh J-H, Jeon I, et al. Trends in burden of workrelated upper limb amputation in South Korea, 2004-2013: a nationwide retrospective cohort study. BMJ Open 2019;9:e032793. doi:10.1136/ bmjopen-2019-032793

- Prepublication history for this paper is available online. To view these files, please visit the journal online (http://dx.doi. org/10.1136/bmjopen-2019032793).

Received 06 July 2019 Revised 25 October 2019 Accepted 30 0ctober 2019

\section{Check for updates}

(c) Author(s) (or their employer(s)) 2019. Re-use permitted under CC BY-NC. No commercial re-use. See rights and permissions. Published by BMJ.

${ }^{1}$ Department of Rehabilitation Medicine, Seoul National University Hospital, Seoul National University College of Medicine, Seoul, Republic of Korea

${ }^{2}$ Department of Rehabilitation Medicine, Korean Workers Compensation and Welfare Service Incheon Hospital, Incheon, Republic of Korea ${ }^{3}$ Institute of Public Health and Medical Service, Seoul NationalUniversity Hospital, Seoul, Republic of Korea

${ }^{4}$ Department of Medicine, Seoul Rehabilitation Hospital, Seoul, Republic of Korea

Correspondence to

Dr Ja-Ho Leigh;

jaho.leigh@gmail.com

\section{ABSTRACT}

Objectives This study aimed to measure the burden of work-related upper limb amputation in Korea over a 10year period and assess its trend.

Design Ecological study.

Setting National level data in Korea between 2004 and 2013.

Participants 49535 subjects who claimed Korea industrial accident compensation insurance due to upper limb amputation.

Main outcome measures The disability-adjusted life years (DALYs) were calculated by sex, age and the site of amputation using annual incidence.

Results The burden of work-related upper limb amputations in Korea reached its peak in 2007 and decreased thereafter. Males showed a higher burden of disease. Finger amputations showed a decreasing trend from 2007, whereas arm amputations continued to show an increasing trend. An increasing trend was found among participants older than 50 years.

Conclusions The decrease in the burden of finger amputations may be attributable to the lower incidence as a result of policy efforts. The increase in the burden of arm amputations was particularly noticeable among the elderly population over 50 years old. This could be attributable to the high proportion of the elderly population working in the manufacturing sector and the lack of policy efforts regarding major amputations in Korea. Future regulatory efforts are needed to prevent amputations.

\section{INTRODUCTION}

Among work-related injuries, amputations are the most serious medically since they can cause permanent physical injury and disability, as well as acute psychological disorder or post-traumatic stress disorder in the future. ${ }^{12}$ In addition, amputations can have an impact on one's entire life by causing loss of earned income due to treatments and loss of future income by acting as a barrier to returning to the workplace. ${ }^{34}$ Upper limb amputations account for most work-related amputations. ${ }^{5}$

Most work-related amputations are preventable. To achieve this, their characteristics
Strengths and limitations of this study

- This study analysed the burden of work-related upper limb amputation in Korea between 2004 and 2013. There are limited studies that analyse the burden of work-related amputations.

- Korea's workers compensation insurance data were used. This is a nation-wide study that covers most industrial accidents

- Because of the lack of data, the cause of an increase in disease burden could not be analysed.

need to be identified first through epidemiological studies that investigate incidence, prevalence and burden of disease (BOD). ${ }^{6}$ However, studies on work-related amputation have been very limited to date, while the scope of most studies has been limited to the regional level and not the national level. Moreover, previous studies mostly investigated the incidence, with almost no studies on the BOD. ${ }^{7}$

Disability-adjusted life years (DALYs), which measure BOD, are calculated as the sum of years of life lost (YLL) due to premature mortality associated with a specific disease and years lost to disability (YLD). The Global Burden of Disease (GBD) study has been conducted worldwide in relation to BOD. The GBD study included an assessment of BOD of work-related injuries. The results showed that work-related injuries constituted approximately $7 \%$ of total disease burden. In addition, the YLD of amputation of upper limb, thumb and fingers was calculated. However, the burden of upper limb amputations due to work-related injuries was not directly estimated. ${ }^{8}$ Most other studies on amputation have only investigated lower extremity amputations due to diabetes or upper limb amputations as general trauma rather than those due to work-related injuries. ${ }^{9} 10$ 
Accordingly, the present study aimed to use national data to calculate the BOD associated with upper limb amputations, which account for the highest percentage of all work-related amputations, and to identify the trend to use the findings as input for the prevention of work-related amputations. Lower limb amputations were excluded because of restricted data. In the GBD study, which deals with BOD of lower extremity amputation, the weight of the disability differs depending on whether the individual uses a prosthesis to replace the amputated limb. Therefore, except for the toes, treatment should be taken into account when calculating DALYs. However, due to the nature of the research data, it was difficult to determine the treatment (such as use of a prosthesis), and therefore the DALYs for lower limb amputation could not be calculated. In this regard, the present study had the following objectives: (1) to calculate the DALYs associated with work-related upper limb amputations over a 10-year period (2004-2013) and (2) to analyse the 10-year trend in DALYs associated with work-related upper limb amputations.

\section{METHODS}

\section{Data source and study population}

This study used the 2004-2013 Korea industrial accident compensation insurance data. In Korea, $98.1 \%$ of businesses with one or more regular employees are enrolled in the industrial accident compensation insurance policy. Because industrial accident compensation must be paid for any injury that requires at least 4 days off work, data for most industrial accidents that have occurred in Korea since 2000 have been collected. These data included information regarding sex, age, occupation, company information (number of workers, industrial classification), medical information (diagnostic code (Korean standard classification of disease and cause of death), year of the accident and grade of disability). ${ }^{11}$

To calculate the BOD of patients with upper limb amputation among all patients from 1 January 2004 to 31 December 2013 who claimed industrial accident compensation, data regarding relevant disease codes were extracted. Related diagnostic codes such as those related to crushing injuries and residual limb were included in order to include as many amputation patients as possible. Thus, the following codes were included: S48.0-1, S48.9, S58.0-1, S58.9, S68.0, S68.00-1, S68.1, S68.10, S68.1009, S68.11, S68.110-9, S68.2-4, S68.40-1, S68.8-9, T05.0-6, T05.8-9, T11.6, T14.5, T14.7, T14.6, T87.3-6 and T92.6. Consequently, we initially selected 51451 patients with work-related amputations. To select the final study population, we excluded those with incomplete amputations $(n=484)$. Because of a limited amount of data, lower limb amputations were excluded $(n=1432)$. As a result, the total number of subjects included in the present study was 49535 (figure 1). Since industrial accident compensation insurance data do not disclose the number of subscribers by gender and age, the working population

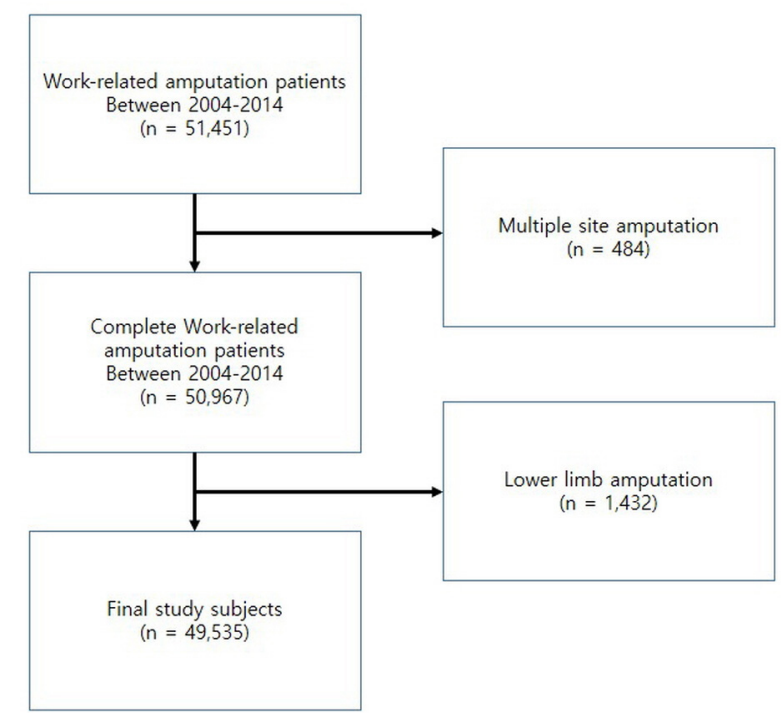

Figure 1 Flow diagram of the study population.

data from the Ministry of Employment and Labor were used as data for the working population for each year. All records were fully anonymised prior to data analysis. Written informed consent was waived because data were collected retrospectively.

\section{Calculation of DALYs}

In order to calculate DALYs, an excel-based DALY calculation template developed by the WHO was used. DALYs were calculated by sex, age (15-19, 20-29, 30-39, 40-49, 50-59 and $\geq 60$ years) and site of amputation (thumb, fingers other than the thumb and arm). Another analysis was performed in order to show trends by age more clearly. In this analysis, the age classification was simplified (15-29, 30-49 and $\geq 50$ years).

In general, when calculating the BOD, DALYs are calculated as the sum of the YLL and YLD. However, because traumatic upper limb amputations do not lead directly to death, YLL values were considered as 0 based on the assumption that there was no premature mortality due to traumatic upper limb amputation. YLD was calculated by multiplying the incidence of upper limb amputation, the duration of injury and disability weight (DW) of the injury. The incidence was calculated separately by sex, age and site of amputation by dividing the number of cases by the size of the working population for each year. The duration of disease was calculated by subtracting the age at the time of amputation from the life expectancy of Koreans in 2013. The DWs from the 2016 GBD study were used. ${ }^{12}$ According to the reference data, we used $0.011 \mathrm{DW}$ for the thumb amputations, 0.005 for the finger amputations and 0.118 for arm amputations. DALYs were standardised for comparison by year. The working population in 2013 was used as the reference population for consistency with a previous study. ${ }^{7}$

\section{Statistical analysis}

Data cleaning was performed by Excel V.2016 (Microsoft, Redmond, Washington, USA). The trend analysis was 
performed using Stata V.15.1 (StataCorp) using a linear regression. We used a two-sided $p$ value $<0.05$ in all analyses as the criterion for statistical significance.

\section{Patient and public involvement}

No patients were involved in developing the research question, outcome measures and overall design of the study. Due to patient anonymity, we are unable to disseminate the results of the research directly to study participants.

\section{RESULTS}

General characteristics are shown in table 1. To investigate the BOD associated with upper limb amputation in Korea from 2004 to 2013, standardised DALYs were calculated. The results showed that DALYs associated with upper limb amputation in Korea continued to increase from 43.00 (per million) in 2004 to a peak of 56.05 (per million) in 2007, after which, a decreasing trend was noted ( $p$ for trend=0.007) (figure 2A). With respect to the amputation site, the DALYs associated with amputations of digits of the hand other than the thumb continued to increase ( $\mathrm{p}$ for trend=0.172) from 18.9 (per million) in 2004 to a peak of 24.75 (per million) in 2007, after which, a decreasing trend was observed. DALYs associated with thumb amputations continued to increase ( $p$ for trend=0.374) from 9.47 (per million) in 2004 to a peak of 14.55 (per million) in 2007, after which, a decreasing trend was observed. DALYs associated with arm amputations continued to increase ( $p$ for trend $=0.003$ ) from 14.5 (per million) in 2004 to a peak of 19.96 (per million) in 2013 (figure 2B). Considering sex, male patients showed a higher BOD associated with upper limb amputation than female patients (figure 3A). Both male and female patients showed an increasing trend of BOD associated with finger amputations (the first and the other four digits of the hand) that reached a peak in 2007 and decreased thereafter. A trend of continuous increase in BOD associated with arm amputations was also noted at this time $(p$ for trend $=0.001$ for male patients, $p$ for trend $=0.063$ for female patients) (figure 3B,C) (table 2).

With respect to age, patients aged 15-49 years showed an increasing trend of BOD associated with upper limb amputation that reached a peak in 2007 and decreased thereafter, while patients $\geq 50$ years $(p$ for trend $=0.004$ for $50-59, \mathrm{p}$ for trend $=0.08$ for over 60 years) showed a continuously increasing trend of BOD (figure 4A). When the patients were divided according to the age groups (15-29, 30-49 and $\geq 50$ years) by the type of amputation (the finger and the arm) for clearer identification of such trends; the BOD trend of thumb and finger amputations in all age groups, even in patients $\geq 50$ years, reached a peak in 2007 and decreased thereafter. However, the BOD associated with arm amputations increased among patients aged $>50$ years ( $p$ for trend $=0.003$ ), while in the 15-29years age group, the BOD associated with arm amputations fluctuated, and in the 30-49years age group,

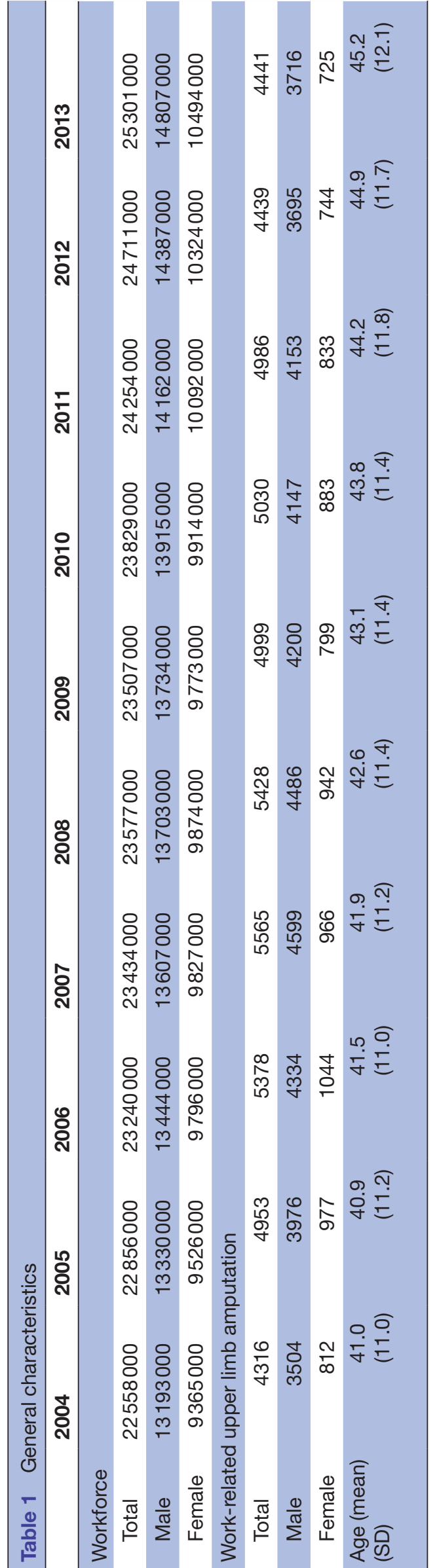




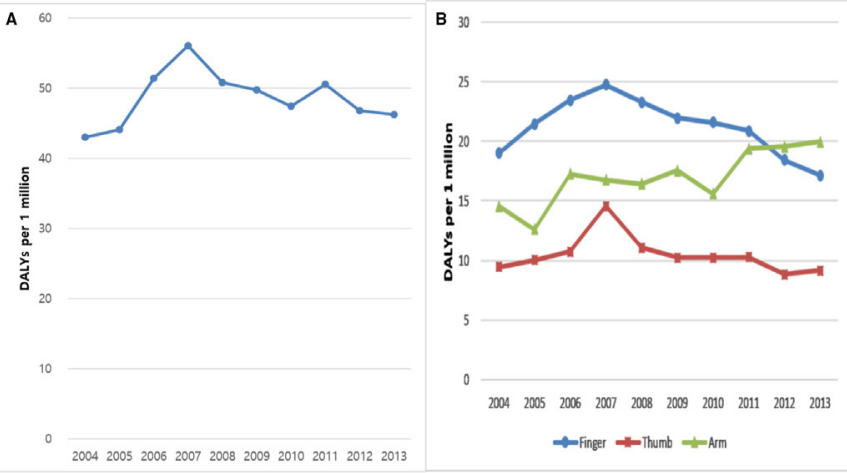

Figure 2 DALY rate of work-related traumatic limb amputations in South Korea from 2004 to 2013: (A) total upper limb amputation and (B) by amputation site. DALY, disability-adjusted life year.

the BOD associated with arm amputations remained stable (figure $4 \mathrm{~B}$ ).

\section{Discussion}

In this study, we calculated DALYs from 2004 to 2013 to investigate the trend in BOD associated with upper limb amputations in Korea. The results showed that the BOD reached a peak in 2007 and decreased thereafter. The same trend was observed in finger amputation (thumb and fingers other than the thumb), whereas arm amputation showed a steadily increasing trend. Such trends were especially noticeable among those aged $\geq 50$ years. Moreover, men experienced a higher BOD than women. Such results could be attributed to the fact that more men than women work in the manufacturing sector and the risk of amputation is higher among businesses with small number of employees. ${ }^{13} 14$
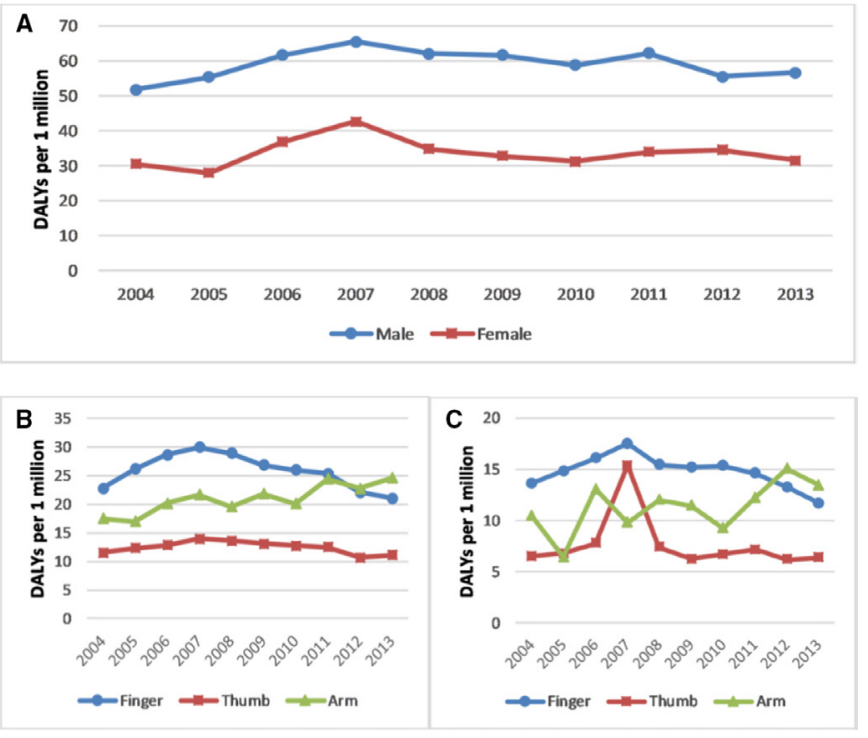

Figure 3 DALY rate of work-related traumatic limb amputations in South Korea from 2004 to 2013: (A) by sex, (B) by amputation site in male patients and (C) by amputation site in female patients. DALY, disability-adjusted life year.
The BOD associated with finger amputation showed a decreasing trend, which was influenced by changes in the incidence. In a previous study on the incidence of workrelated amputations conducted in Korea, the incidence of finger amputation was highest during 2006-2007 and showed a decreasing trend thereafter. The global incidence of finger amputations is also decreasing. The factors contributing to this decreasing trend include stronger government regulation of safety and accident compensation and overseas relocation of factories that engaged in dangerous work. ${ }^{1315}$ Previous studies conducted in Korea also attributed the decrease in the incidence of finger amputation to regular inspection of press or lift machines and the mandatory requirement for submitting plans for risk reduction. ${ }^{7}$

Unlike the BOD associated with finger amputation, the BOD associated with arm amputation showed a continuously increasing trend.

This is different to previous studies on BOD. According to the GBD study, incidence of arm amputation among those aged 50-85 years in Korea is continuously increasing. ${ }^{16}$ However, these results were calculated from publicly available Korean data, and some of the accidents from industrial accidents are missing. The trend of arm amputations in a previous study, which investigated incidence of amputation with the same data source, did not show a steady increase, but it was fluctuated. It was different from the GBD study and this study. BOD can be calculated by incidence, DW and life expectancy. The reason for the difference with this study can be inferred from each item. In terms of incidence, the preceding study only looked at the overall trend, and did not assess the trends by age group. Therefore, the trend could differ due to the difference in incidence ratios between the younger and older age groups for each year's incidence rate. In terms of the DW, the changes in the BOD over time may differ from changes in the incidence, depending on whether the DW is high (eg, arm amputation) or low (eg, thumb amputation). Finally, when the mean age was lower in the 50-year-old or older group, BOD increased with longer disease duration. Although there were some differences from the incidence trend, the GBD study supports the finding that YLDs due to Korean accidents have been continuously increasing from 2004 to 2013.

The increasing BOD associated with arm amputations makes overall upper limb amputation BOD increase among over 50 years. This finding can be interpreted in two ways. First, it is likely due to the industrial structure. Compared with younger people, relatively more people aged $\geq 50$ years work in the manufacturing sector and small businesses that have a higher risk of major amputations. According to a survey of the economically active population in Korea released by Statistics Korea, the proportion of the elderly population aged 55-75 years working in the manufacturing sector among all workers continued to increase from $1.6 \%$ in 2005 to $2.1 \%$ in 2013 , while the proportion of the elderly population among all manufacturing workers also continued 
Table 2 Standardised disability-adjusted life years per million due to work-related upper limb amputations in Korea from 2004 to 2013

\begin{tabular}{lcccccccccc}
\hline & $\mathbf{2 0 0 4}$ & $\mathbf{2 0 0 5}$ & $\mathbf{2 0 0 6}$ & $\mathbf{2 0 0 7}$ & $\mathbf{2 0 0 8}$ & $\mathbf{2 0 0 9}$ & $\mathbf{2 0 1 0}$ & $\mathbf{2 0 1 1}$ & $\mathbf{2 0 1 2}$ & $\mathbf{2 0 1 3}$ \\
\hline Total & 43.00 & 44.08 & 51.40 & 56.05 & 50.80 & 49.73 & 47.41 & 50.54 & 46.79 & 46.23 \\
\hline Finger(s) & & & & & & & & & & \\
$\quad$ Total & 18.99 & 21.44 & 23.45 & 24.75 & 23.31 & 21.97 & 21.57 & 20.89 & 18.43 & 17.13 \\
\hline Male & 22.80 & 26.13 & 28.68 & 29.91 & 28.90 & 26.79 & 25.99 & 25.37 & 22.10 & 21.01 \\
\hline Female & 13.61 & 14.82 & 16.06 & 17.47 & 15.42 & 15.17 & 15.33 & 14.58 & 13.25 & 11.66 \\
\hline Thumb & & & & & & & & & & \\
\hline Total & 9.47 & 10.04 & 10.72 & 14.55 & 11.06 & 10.22 & 10.25 & 10.29 & 8.81 & 9.14 \\
\hline Male & 11.56 & 12.33 & 12.80 & 13.97 & 13.65 & 13.06 & 12.76 & 12.50 & 10.65 & 11.08 \\
\hline Female & 6.50 & 6.81 & 7.77 & 15.37 & 7.41 & 6.22 & 6.72 & 7.17 & 6.20 & 6.40 \\
\hline Arm & & & & & & & & & & \\
\hline Total & 14.55 & 12.60 & 17.24 & 16.75 & 16.44 & 17.53 & 15.59 & 19.36 & 19.55 & 19.96 \\
\hline Male & 17.47 & 16.98 & 20.20 & 21.68 & 19.58 & 21.84 & 20.08 & 24.41 & 22.74 & 24.58 \\
\hline Female & 10.43 & 6.42 & 13.06 & 9.80 & 12.01 & 11.45 & 9.24 & 12.25 & 15.05 & 13.33 \\
\hline
\end{tabular}

to increase steadily, supporting such an interpretation. Second, there is a lack of policy efforts (safety regulations and others) in Korea as regards major amputations. The burden of amputations that are relatively common and minor, like finger amputation, continues to decrease due to heightened awareness and the availability of regulations. However, regulations aimed at preventing major amputations are still lacking. Such an interpretation is supported by the fact that there is no decrease in the BOD associated with arm amputation among all age

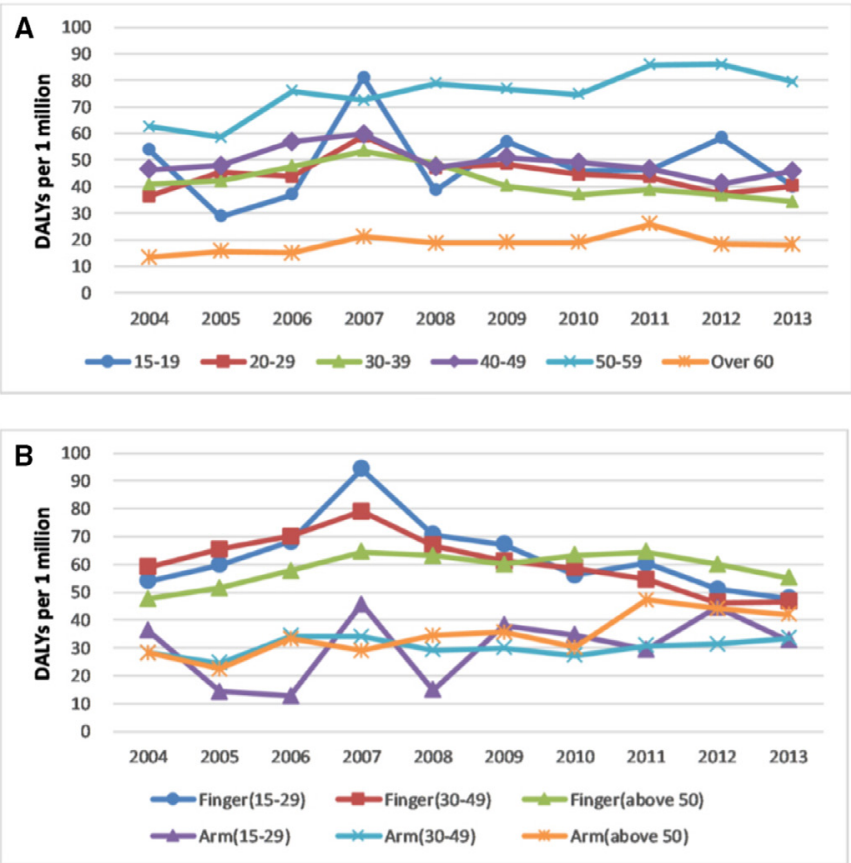

Figure 4 DALY rate of work-related traumatic limb amputations in South Korea from 2004 to 2013: (A) by age and (B) by age and amputation site. DALY, disability-adjusted life year. groups, even when excluding those aged $\geq 50$ years with an increase in the burden of amputations involving all sites. ${ }^{17}$

The significance of the present study was as follows. The study used national industrial accident compensation insurance data to calculate the 10-year BOD associated with work-related upper limb amputations by sex, age and site of amputation, and assessed its trends. The findings could be used as important data to compare the pattern of amputations against the general population or other countries. Policy-wise, the decreasing trend in the BOD associated with finger amputations appears to have been impacted by interest from policy regulations and efforts, whereas the BOD associated with arm amputations, which are major amputations, continued to increase due to the lower effect of policy regulations. Accordingly, regulations and efforts for prevention of major amputations are needed. In particular, because the BOD increased mostly among workers aged $\geq 50$ years, its cause needs to be identified, and policy interest and efforts are also needed.

The present study had the following limitation: first, there may have been an underestimation of BOD due to selection bias. As mentioned above, most of the workplaces were registered, however companies with less than five employees had a $90.1 \%$ registration rate which is somewhat lower than that of larger companies. In addition, due to the nature of the claims data, patients who received treatment for less than 3 days or those whose employers refused to report industrial accidents may have been be excluded. However, because amputations are a serious injury, we expect to receive treatment for more than 3 days and the employer is not likely to avoid reporting. Second, the BOD by occupation and size of the workplace could not be calculated due to lack of data. As a result, we were unable to identify the causes of the increase in BOD which constitutes a limitation. 
Therefore, in future studies, overcoming this limitation in future studies would make it possible to identify the causes of the increase and decrease in BOD associated with upper limb amputations in Korea.

In addition, an age-period-cohort analysis may be conducted to study the effect of policy on the increase or decrease of BOD associated with amputations. Lastly, knowing the circumstance at the time of amputation such as the time of the industrial accident and the average working hours during the week before the industrial accident can help identify the cause of the injury which can inform policy makers.

\section{CONCLUSION}

In the present study, we calculated work-related upper limb amputations between 2004 and 2013. We found that the burden of finger amputations decreased, and the lower incidence was a result of policy efforts and interests. However, the burden of arm amputations increased, particularly among the older population ( $>50$ years). The reason could be industrial structure changes and lack of policy efforts regarding major amputations in Korea compared with minor amputations such as those affecting the fingers. The high rate of arm amputations could also be related to the proportion of the older population working in small-sized companies or within the manufacturing sector, making them vulnerable to major amputations. Future regulatory efforts are needed to help prevent amputations.

Contributors J-sR, J-hL, IJ and MSB contributed to the conception of this article. $\mathrm{J}$-sR, J-hL and IJ performed and interpreted all the analyses of the data. J-sR and $\mathrm{J}-\mathrm{hL}$ were involved in manuscript writing and revisions. All authors read and approved the final manuscript.

Funding This work was supported by a grant from the Research Center for Innovation in Medical Rehabilitation, funded by the Korea Workers' Compensation and Welfare Service.

Competing interests None declared.

Patient consent for publication Not required.

Ethics approval This study was approved by the Institutional Research Ethics Board of the Catholic Medical Center (IRB No. OC17ZESI0088).

Provenance and peer review Not commissioned; externally peer reviewed. Data availability statement № additional data are available.

Open access This is an open access article distributed in accordance with the Creative Commons Attribution Non Commercial (CC BY-NC 4.0) license, which permits others to distribute, remix, adapt, build upon this work non-commercially, and license their derivative works on different terms, provided the original work is properly cited, appropriate credit is given, any changes made indicated, and the use is non-commercial. See: http://creativecommons.org/licenses/by-nc/4.0/.

ORCID iD

Ja-Ho Leigh http://orcid.org/0000-0003-0465-6392

\section{REFERENCES}

1 Sinha R, van den Heuvel WJA, Arokiasamy P. Factors affecting quality of life in lower limb amputees. Prosthet Orthot Int 2011;35:90-6.

2 Stanbury M, Reilly MJ, Rosenman KD. Work-related amputations in Michigan, 1997. Am J Ind Med 2003;44:359-67.

3 Burger $\mathrm{H}$, Marincek $\mathrm{C}$. Return to work after lower limb amputation. Disabil Rehabil 2007;29:1323-9.

4 Rosberg H-E, Carlsson KS, Cederlund RI, et al. Costs and outcome for serious hand and arm injuries during the first year after trauma-a prospective study. BMC Public Health 2013;13:501.

5 Liang H-W, Chen S-Y, Hsu J-H, et al. Work-related upper limb amputations in Taiwan, 1999-2001. Am J Ind Med 2004;46:649-55.

6 Liu S, Li Y, Zeng X, et al. Burden of cardiovascular diseases in China, 1990-2016: findings from the 2016 global burden of disease study. JAMA Cardiol 2019:4:342-52.

7 Jeon I, Leigh J-H, Ro J-S, et al. Trends in the incidence of workrelated traumatic limb amputations in South Korea from 2004 to 2013. Prosthet Orthot Int 2019;43:409-17.

8 Viz Hub. GBD compare. Available: https://vizhub.healthdata.org/gbdcompare [Accessed 1 Sep 2019].

9 dos Santos KPB, da Luz SCT, Mochizuki L, et al. Burden of disease from lower limb amputations attributable to diabetes mellitus in Santa Catarina state, Brazil, 2008-2013. Cadernos de saude publica 2018;34:1.

10 Inkellis $\mathrm{E}$, Low $\mathrm{EE}$, Langhammer $\mathrm{C}$, et al. Incidence and characterization of major upper-extremity amputations in the National trauma data bank. JB JS Open Access 2018;3:e0038.

11 Korea Informative Classification of Disease. Korean standard classification of disease and cause of death, 6 th revision. Available: $\mathrm{http}: / /$ www.koicd.kr/2016/kcd/v6.do\#0\&n [Accessed 1 Sep 2019].

12 WHO. WHO methods and data sources for global burden of disease estimates 2000-2016. Available: https://www.who.int/healthinfo/ global_burden_disease/GlobalDALY_method_2000_2016.pdf

13 Samant Y, Parker D, Wergeland E, et al. Estimating work-related amputations in the Norwegian manufacturing sector: a 10-year retrospective study based on two-source capture-recapture method. Int J Occup Environ Health 2012;18:292-8.

14 Jin K, Lombardi DA, Courtney TK, et al. Patterns of work-related traumatic hand injury among hospitalised workers in the people's Republic of China. Inj Prev 2010;16:42-9.

15 McCall BP, Horwitz IB. An assessment and quantification of the rates, costs, and risk factors of occupational amputations: analysis of Kentucky workers' compensation claims, 1994-2003. Am J Ind Med 2006;49:1031-8.

16 GHDx. GBD results tool. Available: http://ghdx.healthdata.org/gbdresults-tool?params $=$ gbd-api-2017-permalink/7c323b45244076dd aad5f20f2b03266e [Accessed 3 Sep 2019].

17 Statistics Korea. Available: http://kosis.kr/statHtml/statHtml.do? orgld=101\&tblld=DT 1DE8032S\&vw cd=MT ZTITLE\&list id=B1A $20 \&$ seqNo $=\&$ lang_mode $=$ ko\&language $=$ kor\&obj_var_id $=\& i t m \_i d=\&$ conn_path=MT_ZTITLE [Accessed 1 May 2019]. 